\title{
Fixed distraction is not necessary for anterior ankle arthroscopy
}

\author{
Peter A. J. de Leeuw $\cdot$ C. Niek van Dijk
}

Received: 29 June 2009/Accepted: 25 August 2009/Published online: 26 September 2009

(C) The Author(s) 2009. This article is published with open access at Springerlink.com

\section{Dear Editors,}

We have read the article "Treatment of anterolateral impingements of the ankle joint by arthroscopy" by A.-H.M. Hassan with interest, care and appreciation [1].

One of the questions in this publication is whether anterior ankle arthroscopy can routinely be performed without joint distraction.

He states that in patients with anterior ankle soft tissue impingement, distraction will result in tightening of the joint capsule thereby decreasing the anterior working area [1]. These findings are similar to ours [2]. With ankle distraction multiple anatomic structures are pulled tight. The ankle joint capsule has a characteristic difference in comparison with other joint capsules; the anterior capsular insertion in the tibia and talus is located at some distance from the cartilaginous layer. This peculiarity determines the existence of a substantial anterior capsular recess, which creates and allows an anterior working area. The dimension of this working area depends, however, on the position of the foot and ankle. Ankle distraction will reduce the working area, while ankle dorsiflexion creates an anterior capsular recess with subsequent working area [2]. Especially in anterior ankle impingement, the anterior ankle arthroscopic procedure can better and more effectively be performed with the foot and ankle in dorsiflexion,

\footnotetext{
P. A. J. de Leeuw $(\varangle) \cdot$ C. N. van Dijk

Department of Orthopaedic Surgery,

Academic Medical Centre, University of Amsterdam,

PO Box 22700, Amsterdam 1100 DE, The Netherlands

e-mail: p.a.deleeuw@amc.uva.nl; p.a.deleeuw@amc.nl

C. N. van Dijk

e-mail: c.n.vandijk@amc.uva.nl
}

since the created working area will improve visibility and accessibility of this pathology [2-5]. However, later on Hassan argues that with forced plantar flexion the anterior working area opens up [1]. With forced ankle plantar flexion, traction is generated to the anterior ankle joint capsule, which will be pulled tightly, resulting in a reduced anterior working area.

For arthroscopic treatment of talar osteochondral defects forced plantar flexion can bring the defect into the anterior working area $[2,6]$. Treatment of osteochondral defects is not the topic of this paper. We assume therefore, that Hassan has mixed up the foot and ankle position with the arthroscopic treatment of osteochondral defects with that for the treatment of anterior ankle soft tissue impingement lesions.

In conclusion, patients with an anterior ankle impingement lesion should be treated with the ankle in a dorsiflex position and not with routine distraction. This dorsiflex position will allow a better and more effective assessment of the pathology. Distraction or a plantar flexed position will close the anterior working area and will make it more difficult to perform the anterior ankle arthroscopic procedure.

Open Access This article is distributed under the terms of the Creative Commons Attribution Noncommercial License which permits any noncommercial use, distribution, and reproduction in any medium, provided the original author(s) and source are credited.

\section{References}

1. Hassan AH (2007) Treatment of anterolateral impingements of the ankle joint by arthroscopy. Knee Surg Sports Traumatol Arthrosc 15:1150-1154

2. van Dijk CN, Scholte D (1997) Arthroscopy of the ankle joint. Arthroscopy 13:90-96 
3. Lamy C, Stienstra JJ (1994) Complications in ankle arthroscopy. Clin Podiatr Med Surg 11:523-539

4. Sun YQ, Slesarenko YA (2006) Joint distraction may be unnecessary in ankle arthroscopy. Orthopedics 29:118-120
5. Tol JL, van Dijk CN (2006) Anterior ankle impingement. Foot Ankle Clin 11:297-310

6. van Dijk CN, van Bergen CJ (2008) Advancements in ankle arthroscopy. J Am Acad Orthop Surg 16:635-646 